\title{
Design and Fabrication of Water Phantom for Treatment Verification in High Dose Rate (HDR) Brachytherapy of the Cervix
}

\author{
${ }^{1}$ Justice Avevor, ${ }^{2}$ Joseph Amoako, ${ }^{1}$ George Amoako, ${ }^{3}$ Samuel NiiTagoe ${ }^{4}$ Issahaku shirazu \\ 'University of Cape Coast, School of Agriculture and Physical Sciences Faculty of Physical Sciences, \\ Department of Physics, Cape coast, Ghana \\ ${ }^{2}$ Ghana Atomic Energy Commission, Radiation Protection Institute, Accra, Ghana. \\ ${ }^{3}$ National Centre for Radiotherapy and Nuclear Medicine, Accra, Ghana \\ ${ }^{4}$ Radiological and Medical Sciences Research Institute, Ghana Atomic Energy Commission
}

\begin{abstract}
The aim of this study is to design and fabricate a local anatomical water phantom for dose distribution measurements during high dose rate brachytherapy of the cervix. Phantoms for dosimetry are used when there is a need to simulate the conditions of a procedure to measure dose at certain points of interest. It is dangerous to place a human being in a beam for dose measurements. Perspex (PMMA) sheets of thickness $6 \mathrm{~mm}$ and $10 \mathrm{~mm}$ were used for fabricating the phantom. The phantom designed is cuboid in shape with predominantly $6 \mathrm{~mm}$ thickness of the perspex material. It has a height of $41 \mathrm{~cm}$ and breadth $31 \mathrm{~cm}$. The pieces of perspex material were glued to each other using Trichloromethane (chloroform) at room temperature. It is an organic compound with the formula $\mathrm{CHCI}_{3}$. A perspex sheet of $10 \mathrm{~mm}$ was used to make one end of the phantom thicker than the other. This was done to support the reconstruction box. Two thin film holder slabs of dimensions $31.5 \times 2.8 \mathrm{~cm}^{2}$ were fabricated by joining two sheets of $6 \mathrm{~mm}$ perspex together with the chloroform. A small cavity of $2.8 \times 2.5 \mathrm{~cm}^{2}$ was created in the slab to represent the bladder and the rectum (organs at risk). These same cavities are meant to hold the detectors (films) in place for the measurement of dose to the organs at risk. The film holders with the cavities were then positioned vertically, but anterior and posterior to each other. Another holder, rectangular in shape was fabricated to hold the film holders. This holder was made from perspex sheets of thickness $6 \mathrm{~mm}$ and $10 \mathrm{~mm}$ with dimensions of $6.8 \times 6.8 \mathrm{~cm}^{2}$. This is to allow for the distances between the bladder and the rectum to be varied during the dose measurements. It must be noted that the anatomical distance between the bladder and the rectum which are posterior and anterior to the cervix vary from patients to patients. Special clamping devices were fabricated to hold the applicators in a firm position during the intracavitary brachytherapy insertions. These special clamps were made by joining perspex of $10 \mathrm{~mm}$ thickness in a cuboid shape; a hole was drilled in them to enable a plastic screw to lock the applicators. The relative electron density of the phantom designed was determined to be 1.069 which is comparable to water. This makes the phantom suitable for dose distribution measurements.
\end{abstract}

Keywords :Perspex Sheets, Phantom, Dose, HDR Brachytherapy

\section{INTRODUCTION}

Dosimetry investigations in radiotherapy involve mostly the use of phantoms. This is because the
Perspex materials used in the construction of these phantoms mimic the anatomical properties of the human tissues. Phantoms therefore, represent the 
human body and have been in use for investigations as far as treatments with radiations are concerned.

In 1896, after Wilhelm Conrad Rontgen discovered $\mathrm{x}$ rays, her wife's hand was first used for the world's first ever $\mathrm{x}$ ray images. The effects were harmful due to high doses of radiation received and that resulted in erythema and cell squamation. As a result, nobody was willing to volunteer for radiation exposures meant for experimental purposes. This is what led to the development of phantoms by physicists to simulate patients for dose measurements and to also verify the effectiveness of the system.

In designing a phantom, the materials are selected based on the intended use of the phantom. The thickness of the material, the size, shape of the phantom fabricated will depend on what it is fabricated for. Phantoms that are meant to use dosimeters like film or TLDs also have different designs and fabrications. Every material used in the phantom design must simulate human tissues, but the properties of these materials vary with the amount of radiation energies incident upon them. The materials will be tissue equivalent based on a range of energies they receive; they cannot be tissue equivalent over all range of energies.

\section{OBJECTIVE}

The objective of this study is to design and fabricate a local anatomical water phantom for dose distribution measurements during high dose rate brachytherapy of the cervix.

\section{METHODS AND MATERIAL}

\section{MATERIALS}

The following materials were used in construction the phantom for dose distribution measurement: Perspex
(PMMA) sheets of thickness $6 \mathrm{~mm}$ and $10 \mathrm{~mm}$, Trichloromethane (chloroform) and a tape measure.

\section{METHOD}

Perspex (PMMA) sheets of thickness $6 \mathrm{~mm}$ and $10 \mathrm{~mm}$ were used in the entire design as shown in figure 1. CT images of a real patient's cervical region were obtained from the CT scanner and these were used in constructing the bladder and rectal region of the cervix phantom.

The phantom designed is cuboid in shape with predominantly $6 \mathrm{~mm}$ thickness of the perspex material. It has a height of $41 \mathrm{~cm}$ and breadth $31 \mathrm{~cm}$. The pieces of perspex material were glued to each other using Trichloromethane (chloroform) at room temperature. The chloroform was used to join the perspex sheets together. It is an organic compound with the formula $\mathrm{CHCI}_{3}$. Chloroform is a colorless, volatile liquid derivative of Trichloromethane with an ether-like odour. It can be used as a solvent to bond pieces of acrylic glasses together.

A perspex sheet of $10 \mathrm{~mm}$ was used to make one end of the phantom thicker than the other. This was done to support the reconstruction box. Two thin film holder slabs of dimensions $31.5 \times 2.8 \mathrm{~cm}^{2}$ were fabricated by joining two sheets of $6 \mathrm{~mm}$ perspex together with the chloroform.

A small cavity of $2.8 \times 2.5 \mathrm{~cm}^{2}$ was created in the slab to represent the bladder and the rectum. These same cavities are meant to hold the gafchromic films in place for the measurement of dose to the bladder and the rectum which are the organs at risk (OAR) in the treatment of cervical cancer. The film holders with the cavities were then positioned vertically, but anterior and posterior to each other in the cuboid shaped water phantom designed. 
Another holder, rectangular in shape was fabricated to hold the film holders. This holder was made from perspex sheets of thickness $6 \mathrm{~mm}$ and $10 \mathrm{~mm}$ with dimensions of $6.8 \times 6.8 \mathrm{~cm}^{2}$. This is to allow for the distances between the bladder and the rectum to be varied during the dose measurements. It must be noted that the anatomical distance between the bladder and the rectum which are posterior and anterior to the cervix vary from patients to patients.

Special clamping devices were fabricated to hold the applicators in a firm position during the intracavitary brachytherapy insertions. These special clamps were made by joining perspex of $10 \mathrm{~mm}$ thickness in a cuboid shape; a hole was drilled in them to enable a plastic screw to lock the applicators. Figure 1 depicts the fabricated phantom.

The relative electron density of the perspex sheet used in the entire design was determined to be 1.069 which is comparable to that of water. This makes the phantom suitable for dose distribution measurements. The cross sectional view of the phantom is shown in figure 2.

\section{RESULTS AND DISCUSSION}

The phantom was design to meet certain design criteria so that it can test realistic anatomic clinical situations. The relative electron density of the perspex sheet used in the entire design was determined to be 1.069 which is comparable to water. This makes the phantom suitable for dose measurements. The perspex materials used mimic radiological properties when irradiated. The phantom was filled with water because greater part of the human body weight is made up of water. Water was used as substitute for tissues and bones.

The human adult body is made up of $60 \%$ water. The brain and heart are composed of $73 \%$ water, and the lungs are about $83 \%$ water. The skin contains $64 \%$ water, muscles and kidneys are $79 \%$, and even the bones are 31\%. (H.H. Mitchell, 1945) Water is an appropriate material because it has the advantage of conducting electricity as required for electron measurements (Glabraith et al., 1984) and is universally available. The PMMA material used in constructing the phantom and the water are homogenous; they are the only substitute for tissue and muscles in a real patient when considering BT treatment.

Dosimetry protocols require that dose measurement test be carried out using phantoms because it is very risky and dangerous using real patients for such tests since exposure to radiations could cause cancers. The phantom constructed gave very good and convincing results and therefore can be used for further in vivo dosimetry at the centre. The phantom constructed gave very good and convincing results and therefore can be used for further in vivo dosimetry study.

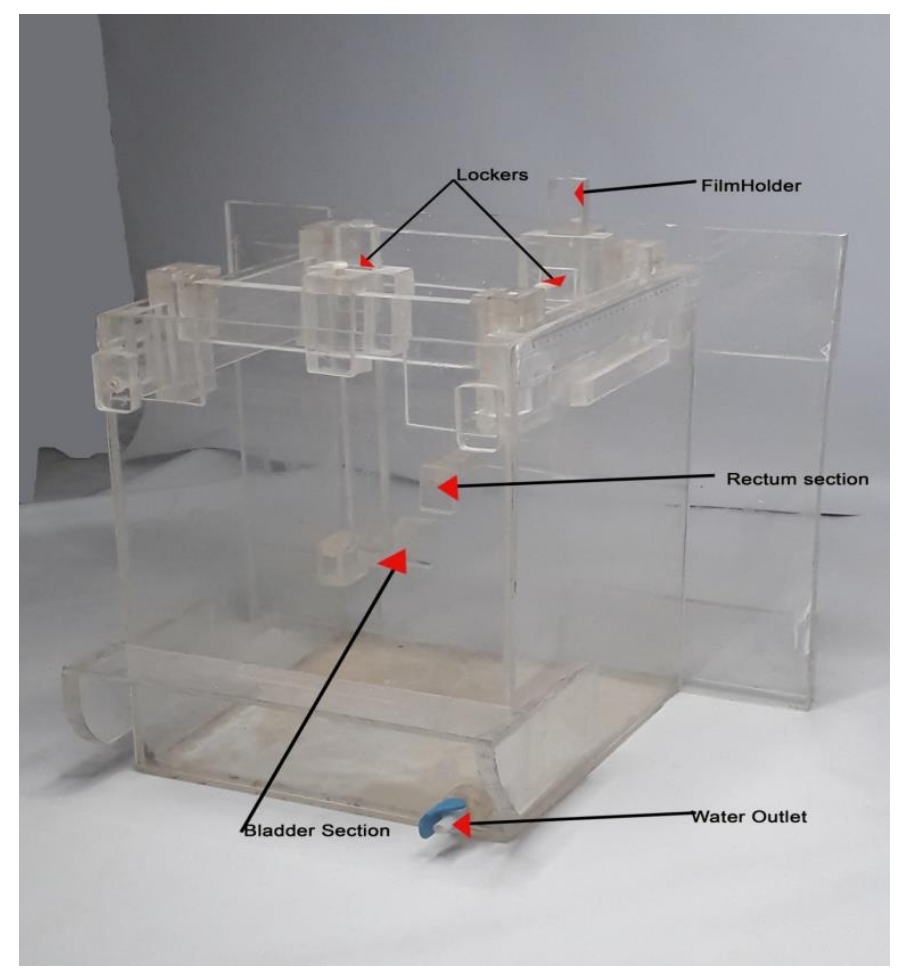

Figure 1: Locally constructed water phantom 


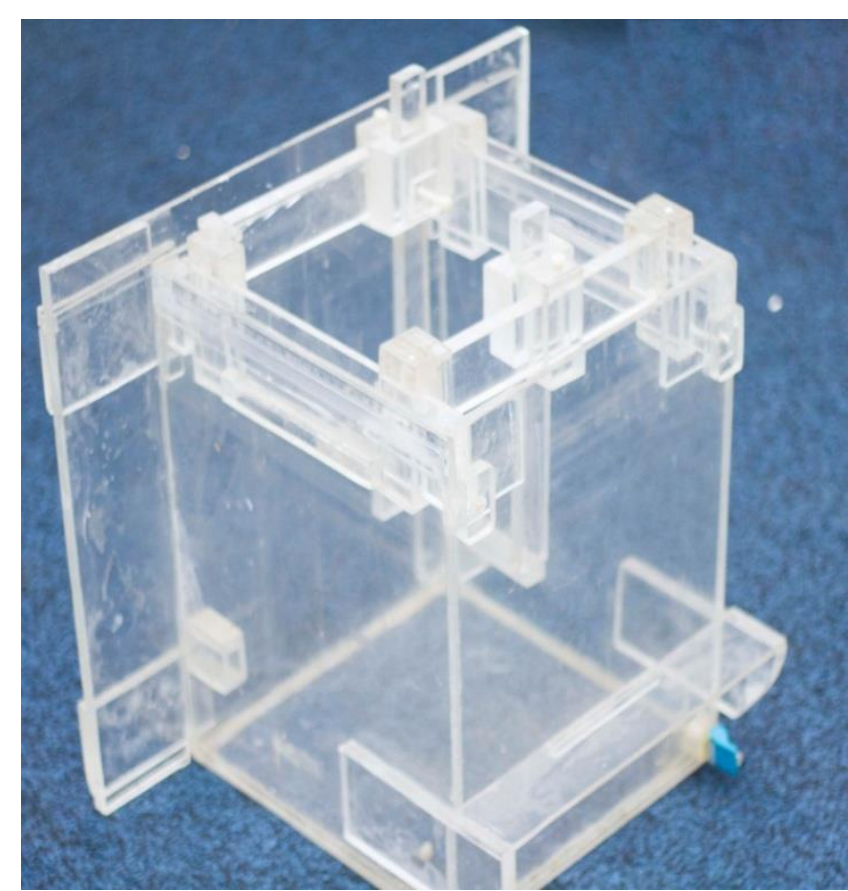

Figure 2: Cross sectional view of the locally constructed water phantom

\section{IV.CONCLUSION}

The results from this research suggested that the locally constructed phantom is suitable and can be used for dose distribution measurements and system verification during high dose rate (HDR) brachytherapy of the cervix. The results have shown that the fabricated phantom mimic radiological and anatomic properties of tissues, hence make it suitable for dose distribution measurements and further research work relating to cervical cancer. The perspex materials mimic radiological properties and can be used for constructing any local phantom for research purposes. The electron density of the perspex materials is comparable to that of water.

\section{RECOMMENDATION}

The phantom constructed from this study gave convincing results and it is therefore recommended for clinical applications.

\section{ACKNOWLEDGEMENT}

My highest appreciation goes to the most high God for His goodness and love. Special thanks to the University of Cape Coast, the Graduate School, Department of Physics and the National Centre for Radiotherapy and Nuclear Medicine.

\section{REFERENCES}

[1]. Galbraith, D.M., Rawlison, J.A., and Munro,P. (1984). Dose errors due to charge storage in electron irradiated plastic phantoms. Med. Physics., 21, 16059

[2]. International Atomic Energy Agency. Radiation protection and safety of radiation sources: international basic safety standards. International Atomic Energy Agency, Vienna, 2014. Pp. 16- 27.

[3]. Jamema SV, Mahantshetty U, Tanderup K, Malvankar D, Sharma S, Engineer R, et al. Interapplication variation of dose and spatial location of $\mathrm{D}(2 \mathrm{~cm}(3))$ volumes of OARs during MR image based cervix brachytherapy. Radiother. Oncol 2013; 107: 58-62. doi: 10.1016/j.radonc.2013.01.011

[4]. Jones AK, Hintenlang DE, Bolch WE. Tissueequivalent materials for construction of tomographic dosimetry phantoms in pediatric radiology. Med Phys. 2003;30(8):2072-81.

[5]. A. Kapulsky, E. Mullokandov, and G. Gejerman, "An automated phantom-film QA procedure for intensity-modulated radiation therapy," Med Dosi 27 (3), 201207 (2002).

[6]. Mitchell H.H., Hamilton T.S Ii'. Steggerda R., And Bean H.W. (1945) "The Chemical Composition Of The Adult Human Body And Its Bearing On The Biochemistry Of Growth" Journal of Biological Chemistry, P158.

[7]. DeWerd, L.A. and Kissick, M. (2014) "The Phantoms of Medical and Health Physics: Devices for Research and Development". Springer, Heidelberg NY, (1), 114. 
Cite this article as: Justice Avevor, Joseph Amoako,

George Amoako, Samuel Nii Tagoe, Issahaku shirazu

"Design and Fabrication of Water Phantom for

Treatment Verification in High Dose Rate (HDR) Brachytherapy

of the Cervix", International Journal of Scientific Research

in Science and Technology (IJSRST), Online ISSN : 2395-

602X, Print ISSN : 2395-6011, Volume 6 Issue 5, pp. 211-

214, September-October 2019. Available at doi :

https://doi.org/10.32628/IJSRST196518

Journal URL : http://ijsrst.com/IJSRST196518 